\title{
The "Gandalf" soil sampling project at a former industrial site in Copenhagen, Denmark: evaluating soil classification reliability
}

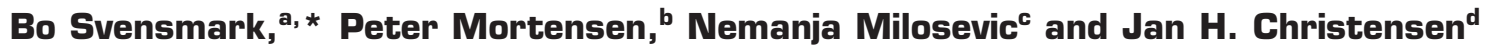 \\ ${ }^{a}$ Associate Professor Emeritus, Department of Plant and Environmental Sciences, University of Copenhagen, \\ Thorvaldsensvej 40, 1871, Frederiksberg C, Denmark \\ bManager, Research and Development at Eurofins Environment Denmark, Ladelundvej 85, DK-6600 Denmark \\ 'Specialist, MOE A/S engineering consultancy, Buddingevej 272, 2680, Søborg, Denmark \\ dProfessor, Department of Plant and Environmental Sciences, University of Copenhagen, Thorvaldsensvej 40, 1871, \\ Frederiksberg C, Denmark
}

Handling and transport of contaminated soil from industrial sites in Denmark requires classification based on concentrations of selected metals and organic contaminants. Reliable soil classification is needed for defensible remedial decision-making. Today's sampling process in Denmark is based on grab sampling of prescribed standard volumes of soil; 30 tons is typically used as the basic sampling Decision Unit. Soil classification follows a number of varying systems, but classification into five classes (class 0 to class 4 ) based on analytical results from sub-samples of $50 \mathrm{~g}$ is the most common. In this study, we investigate the sampling uncertainty obtained by sampling of $>1800$ samples at a former industrial site in Copenhagen, Denmark. The aim of the study was to conduct a critical assessment of the current sampling strategy by determination of soil classification errors obtained for duplicate primary samples and for secondary samples collected from the same truck-load of soil but with different distances from the original primary sample. It is also discussed which contaminants are the major parameters responsible for final soil classification designations.

\section{Introduction}

Our results demonstrate that across the site, the general sampling uncertainty over the many different contaminants included was at least 60-70\%. More interesting, 53\% of the replicates within the same primary sampling Decision Unit (DU) were classified differently

\section{DOI: $10.1255 /$ sew.2021.a29}

(c) 2021 The Authors

Published under a Creative Commons BY-NC-ND licence

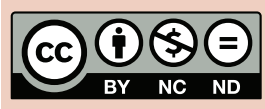

from one another. Soil classification errors increase as a function of distance between samples up to a distance of $2 \mathrm{~m}$ where the classification error stabilises close to $60 \%$ (some samples were misclassified with up to four class designations). Metals had the highest difference percentages with respect to alternative soil classifications, whereas lower percentages were obtained for Polycyclic Aromatic Hydrocarbons (PAHs), hydrocarbons and especially BTEX (benzene, toluene ethylbenzene and xylenes), reflecting low concentrations (often < detection limit, DL) which results in a massive class 0 classification bin ("clean soil").
When following currently prescribed sampling strategies, this investigation on a scale of an entire industrial parcel demonstrates that primary and secondary sampling errors are the main factors affecting soil classification. At least 50\% of all samples are misclassified with potential significant negative consequences for ecosystems, public health and project economy. Thus, the Theory of Sampling (TOS) must be called in as a tool for improving the quality of data to be used for decision-making.

\section{Background}

Worldwide, former industrial sites are transformed into housing and office areas 


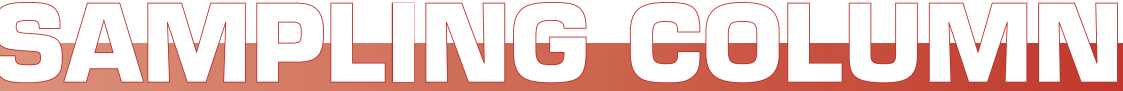

mainly due to densification of city areas. Because of former industrial production, storage of chemicals, raw materials (including soil from other sites), waste and petroleum fuels in underground and above-ground tanks and atmospheric deposition of airborne contaminants from the surrounding city areas, site soils often display complex contamination patterns. These contaminants include heavy metals, hydrocarbons, pesticides, chlorinated and bromated biphenyls etc.

Approximately 14,000 sites in Denmark, urbanised or industrialised before 1983, are expected to be contaminated due to former industrial use. 'After 1983, the first legislation dealing with contaminated sites was enacted (The Chemical Waste Deposit Act, 1983). Nowadays, in the absence of a dedicated EU directive on soil, ${ }^{2}$ chemical impact assessment at these former industrial sites together with excavation, transportation and reuse of soils are regulated by a set of national rules ${ }^{3-5}$ alongside a number of regional interpretations and recommendations.

\section{Soil classification}

For new construction projects, current Danish regulations demand that soil planned for excavation must be classified according to the level of contamination of selected contaminants before excavation and transport. One sample (grab sampling) shall be extracted for every DU, which is 30 tons of soil, corresponding to one truck-load.

The most frequently used regional recommendation in the City of Copenhagen is "Jordplan Zealand". 6 According to this, soils are classified into five classes according to the contamination levels of metals, BTEX, hydrocarbons and PAHs from class 0 for clean soil to class 4 for heavily contaminated soil according to the concentrations, ${ }^{6}$ see Table 1. The samples are classified according to the highest class for the individual compounds/parameters. The classification of excavated soils regulates their reuse. Class 0 can thus be reused for any purpose, whereas class 4 must be cleaned before reuse or deposited on landfill. Typically, the aim of soil classification on construction

Table 1. Threshold limits for contaminants in $\mathrm{mg} \mathrm{kg}^{-1} \mathrm{dw}$ (dry weight). ${ }^{5}$

\begin{tabular}{|c|c|c|c|c|c|c|}
\hline \multirow{2}{*}{\multicolumn{2}{|c|}{ Compound }} & \multicolumn{5}{|c|}{ Class } \\
\hline & & 0 & 1 & 2 & 3 & 4 \\
\hline Cadmium & $\mathrm{Cd}$ & 0.5 & 0.5 & 1 & 5 & $>5$ \\
\hline Chromium & $\mathrm{Cr}$ & 50 & 500 & 500 & 750 & $>750$ \\
\hline Copper & $\mathrm{Cu}$ & 30 & 500 & 500 & 750 & $>750$ \\
\hline Nickel & $\mathrm{Ni}$ & 15 & 30 & 40 & 100 & $>100$ \\
\hline Lead & $\mathrm{Pb}$ & 40 & 40 & 120 & 400 & $>400$ \\
\hline Tin & Sn & 20 & 20 & 50 & 200 & $>200$ \\
\hline Zinc & $\mathrm{Zn}$ & 100 & 500 & 500 & 1.5 & $>1500$ \\
\hline Benzene & Benzene & 0.1 & 0.1 & 1.5 & 2.5 & $>2.5$ \\
\hline BTEX & BTEX & 0.6 & 0.6 & 10 & 15 & $>15$ \\
\hline Light oil & C10-C20 & 55 & 55 & 83 & 110 & $>110$ \\
\hline Light oil & C $10-C 15$ & 40 & 40 & 60 & 80 & $>80$ \\
\hline Light oil & C15-C20 & 55 & 55 & 83 & 110 & $>110$ \\
\hline Heavy oil & C20-C35 & 100 & 100 & 200 & 300 & $>300$ \\
\hline Volatiles & C6-C10 & 25 & 25 & 35 & 50 & $>50$ \\
\hline Oil total & C6-C35 & 100 & 100 & 200 & 300 & $>300$ \\
\hline Benz(a)pyrene & BaPyr & 0.1 & 0.3 & 1 & 5 & $>5$ \\
\hline $\begin{array}{l}\text { Dibenz }(a, h) \\
\text { anthracene }\end{array}$ & DBahAnt & 0.1 & 0.3 & 1 & 5 & $>5$ \\
\hline PAH & PAH & 1 & 4 & 15 & 75 & $>75$ \\
\hline
\end{tabular}

sites is either to delineate clean soil if the site does not have a record of industrial land use or to delineate heavily contaminated soil in former industrial sites.

\section{Study objective}

The aim for this study is to critically assess the sampling strategy used for classification of contaminated, urban filled-in soil in Denmark using grab sampling of one sample per 30 tons of soil. As urban filled-in soil is a heterogeneous material, an improper sampling strategy would lead to biased results due to large uncertainties derived from non-representative sampling. Subsequently, high uncertainties will lead to incorrect contaminant classification. This study includes characterisation and evaluation of the current sampling protocol.

\section{Study design}

This study was performed on soil samples from an industrial site in Copenhagen. As part of an innovation project funded by
Innovation Fund Denmark (GANDALF: Untargeted Fingerprinting Analysis and GIS Visualization of Contaminants - $A$ New Paradigm for Chemical Impact Assessment in Urban Development), 1848 samples were extracted from a site in Copenhagen. The samples collected for soil classification are named "standard samples" in this paper. For the Gandalf project, this situation was ideal because a lot of samples and results for the contaminants listed in Table 1 were made available without extra cost. Standard samples were collected in $7 \times 7 \mathrm{~m}$ grids, while additional samples were collected to investigate the distributional heterogeneity of the soil with a spatial resolution finer than $7 \mathrm{~m}$. These extra samples, named "Gandalf samples", were collected at $1 \mathrm{~m}, 2 \mathrm{~m}$ and $3 \mathrm{~m}$ distances from the standard samples. This paper describes the site, the sampling, the results and what we have learned regarding the sampling part of the project and the consequences for soil classification in general. 


\section{Methods and materials Site description}

The sampling site is a post-industrial location in Copenhagen, covering an area of $11,369 \mathrm{~m}^{2}$. A glue factory was located on the site a century ago, and 30 years later a paint and lacquer factory took over the site. At the end of the last century the property was used for warehousing, stock rental and container rental. Furthermore, tanks and drums containing chemicals and waste were stored on the site. The historical map is shown in Figure 1.

\section{Standard samples}

Standard samples were collected as part of mandated soil classification before excavation of the site. Sampling was performed by the consulting engineering company MOE (https://www. moe.global/). The sampling of standard samples was planned according to legislation and standard protocols for sampling of contaminated sites, which stipulates grab sampling of one sample per 30 tons of soil.
As part of the classification, the site was divided into 216 squares of $7 \times 7 \mathrm{~m}$ $\left(49 \mathrm{~m}^{2}\right)$ adjusted to fit the shape of the area and the footprint of the new building to be erected (see Figures 1 and 2a). In the 158 squares covering the location of the new buildings (B-sampling lots), nine standard samples were generally collected with $33 \mathrm{~cm}$ depth intervals to a depth of $3.00 \mathrm{~m}(0.00-0.33 \mathrm{~m}, 0.34-$ $0.66 \mathrm{~m}, 0.67-1.00 \mathrm{~m}, 1.01-1.33 \mathrm{~m}$, $1.34-1.66 \mathrm{~m}, 1.67-2.00 \mathrm{~m}, 2.01-2.33 \mathrm{~m}$, $2.34-2.66 \mathrm{~m}$ and $2.67-3.00 \mathrm{~m}$ ).

In the 58 squares located outside the footprint of the new buildings (M-sampling lots), two depth samples $(0.00-0.33 \mathrm{~m}$ and $0.67-$ $1.00 \mathrm{~m}$ ) were collected, Figure 2a. There were some exceptions to this due to project adjustments, i.e. some samples were not collected or not analysed, and $16 \mathrm{M}$-sampling lots were sampled at all depths down to $3 \mathrm{~m}$, see Table 2 for a complete overview of the number and types samples collected. Figure $2 b$ shows the sampling process.

\section{Gandalf samples}

Gandalf samples were used to estimate the distributional heterogeneity down to $1 \mathrm{~m}$, and to serve as duplicates of the primary samples, as all Gandalf samples were collected inside the $49 \mathrm{~m}^{2}$ DU squares where a standard sample also was taken.

The position of the Gandalf samples is at a distance of $1 \mathrm{~m}, 2 \mathrm{~m}$ or $3 \mathrm{~m}$ from the standard sample position in four directions along, and perpendicular to, the main grid orientation. With a distance of $1 \mathrm{~m}, 2 \mathrm{~m}$ and $3 \mathrm{~m}$ from one standard sample position, the distance to the neighbouring standard sample position will be $6 \mathrm{~m}, 5 \mathrm{~m}$ and $4 \mathrm{~m}$, i.e. this design gives samples in all distances of $1 \mathrm{~m}, 2 \mathrm{~m}, 3 \mathrm{~m}, 4 \mathrm{~m}, 5 \mathrm{~m}$ and $6 \mathrm{~m}$ from a standard sample position.

To reduce sampling and analysis costs, Gandalf samples were collected only for two of every three standard sample positions (110 of 158 positions), and at two or three depths only, see Table 2. In contrast, standard

\section{Demolished buildings Former buildings \\ - Drum storage sludge basin Tank above ground Tank underground}

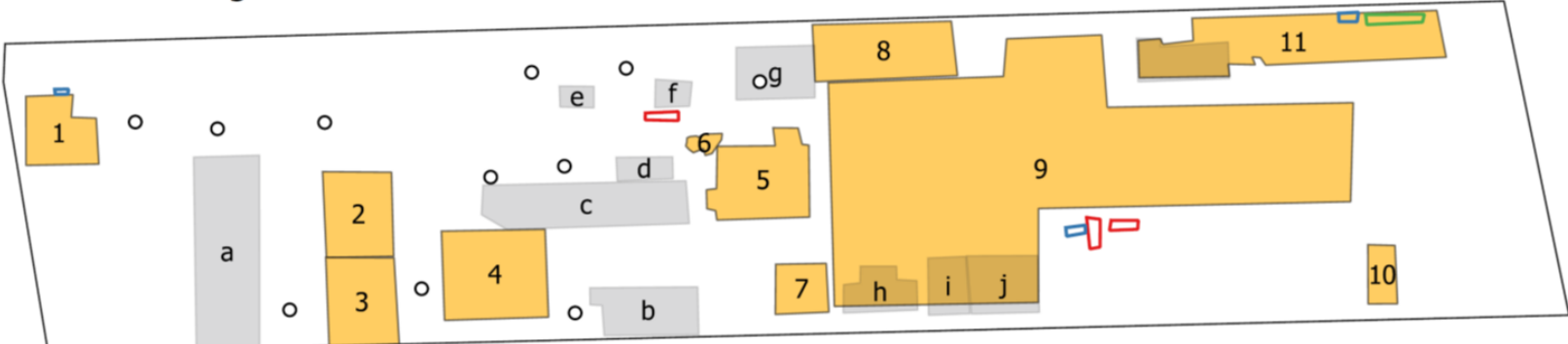

$\begin{array}{ll}1 & \text { Office building } \\ 2 & \text { Stock } \\ 3 & \begin{array}{l}\text { Storage of drums, nitro } \\ \text { cellulosek }\end{array} \\ 4 & \text { Stock } \\ 5 & \begin{array}{l}\text { Workshop, welding shed, } \\ \text { distillation plant }\end{array} \\ 6 & \text { Boiler room, chimney }\end{array}$

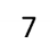

8

Residential

Silverware factory

laboratory, metal grinder

9 Glue factory, Machinery factory, Weaving mill

10 Unknown building

11 Workshop a, c, d Storage shed

b Garage and stock spray booth

$e, f \quad$ Fuel shed

g Stock

h Carpentry

i, j Unknown objects

Figure 1. The site based on the historical report. ${ }^{7}$ 


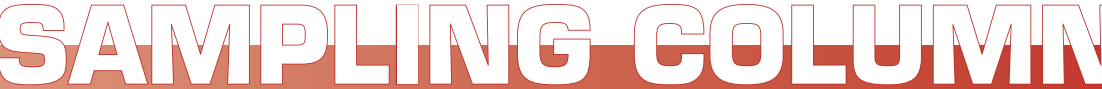
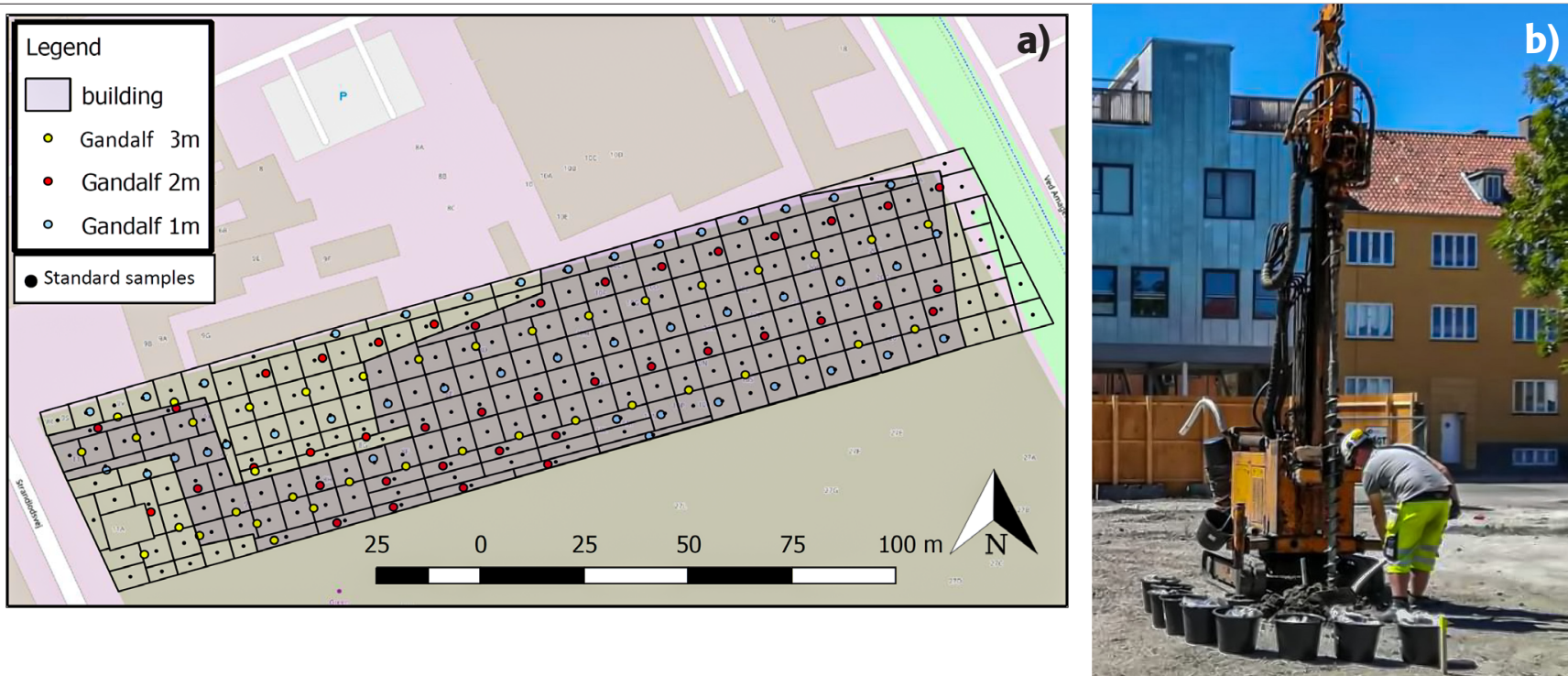

Figure 2. a. Site map with all sample positions. Inside the perimeter of the new building (shaded) for each position standard samples were collected at nine depths, while only two depth samples were collected from outside positions. The larger yellow, red and blue circles denote the location of the additional Gandalf samples collected at $1 \mathrm{~m}, 2 \mathrm{~m}$ and $3 \mathrm{~m}$ distances from the standard samples. b. Sampling of primary samples (picture is provided by MOE engineering consultancy). Each bucket contains a one-increment primary sample from nine different depths. Samples were scraped off the drill and deposited into plastic bags inside buckets to avoid cross-contamination.

Table 2. Number of samples as function of depth, designated by the relevant interval centre, e.g. $0.17 \mathrm{~m}$ is the centre of $0.00-0.33 \mathrm{~m}$. "B" indicate samples collected inside the new building perimeter, while " $\mathrm{M}$ " indicate samples collected outside.

\begin{tabular}{|c|c|c|c|c|c|c|c|c|c|}
\hline $\begin{array}{l}\text { Depth } \\
(\mathrm{m})\end{array}$ & Standard B & Gandalf B & Standard M & Gandalf $\mathrm{M}$ & $\begin{array}{c}\text { Standard } \\
B+M\end{array}$ & $\begin{array}{c}\text { Gandalf } \\
B+M\end{array}$ & $\begin{array}{c}\text { Gandalf } \\
1 \mathrm{~m}\end{array}$ & $\begin{array}{c}\text { Gandalf } \\
2 \mathrm{~m}\end{array}$ & $\begin{array}{c}\text { Gandalf } \\
3 \mathrm{~m}\end{array}$ \\
\hline 0.17 & 158 & 88 & 58 & 22 & 216 & 110 & 34 & 39 & 37 \\
\hline 0.5 & 141 & 1 & 16 & 5 & 157 & 6 & 0 & 0 & 6 \\
\hline 0.83 & 141 & 84 & 34 & 21 & 175 & 105 & 31 & 37 & 37 \\
\hline 1.17 & 141 & 0 & 16 & 5 & 157 & 5 & 0 & 0 & 5 \\
\hline 1.5 & 141 & 0 & 16 & 5 & 157 & 5 & 0 & 0 & 5 \\
\hline 1.83 & 141 & 0 & 16 & 5 & 157 & 5 & 0 & 0 & 5 \\
\hline 2.17 & 141 & 0 & 16 & 5 & 157 & 5 & 0 & 0 & 5 \\
\hline 2.5 & 140 & 1 & 16 & 5 & 156 & 6 & 0 & 1 & 5 \\
\hline 2.83 & 140 & 53 & 16 & 4 & 156 & 57 & 17 & 20 & 20 \\
\hline
\end{tabular}

samples were collected at three or nine depths, respectively. Figure 3 shows the position of all Gandalf samples relative to the standard sample grid.

As shown in Figures 2 and 3, the Gandalf samples were collected in the same direction for a standard sampling transect in order to simplify the job for the sampling team. The positions for the Gandalf samples were not measured by GPS but calculated relative to the closest standard sample position.
Sampling

Sampling was performed by a rotary auger (diameter $=10 \mathrm{~cm}$ ), Figure $2 \mathrm{~b}$. The outermost $1-2 \mathrm{~cm}$ of the drilled soil column was removed by knife before the rest of each $33 \mathrm{~cm}$ length primary samples were transferred to a bucket and mixed. Each primary sample corresponds to a lot of approximately 30 tons $\left(7 \times 7 \times 0.33 \mathrm{~m} \times 1.85\right.$ tons $\left.^{-3}\right)$ and had a weight of approximately $3.7 \mathrm{~kg}$, which corresponds to a primary sampling rate $\sim 1: 8000(\mathrm{~m} / \mathrm{m})$.
After manual mixing with a spoon, or by hand and removal of extraneous rocks and plastic materials, secondary samples of approximately $50 \mathrm{~g}$ were constructed by randomly spoon-collecting a minimum of 10 increments from each primary sample. Secondary samples were transferred to glass containers with a septum (blue cap) and to a Rilsan ${ }^{\circledR}$ bag (nylon) for analysis, and were stored in cooling containers after sampling and during transportation. The secondary sampling corresponds to a $\sim 75$ mass 


\section{SAMUPANEGOLENW}

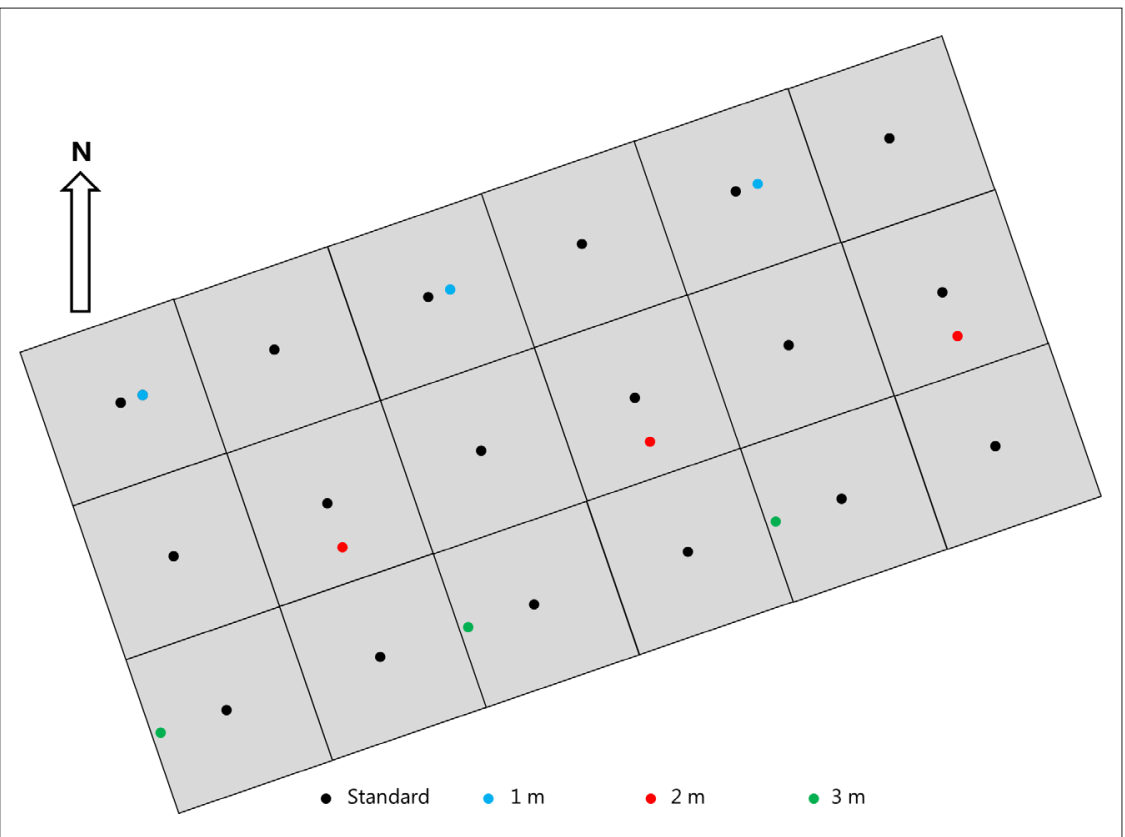

Figure 3. Gandalf sample positions relative to standard samples, shown for $1 \mathrm{~m}$ sample in an easterly direction (right side of the standard samples), $2 \mathrm{~m}$ samples in a southerly direction (below standard samples) and $3 \mathrm{~m}$ samples in a westerly direction (left of standard samples). The exact position of all Gandalf samples can be seen in Figure 2.

reduction rate. The only difference from the official standard sampling method is the use of 10 increments in the Gandalf project instead of one.

Thus overall, extracting $50 \mathrm{~g}$ analytical samples from DUs of 30 tons corresponds to a massive $1: 600,000$ sampling rate. From current official guidelines it is assumed that such a sampling rate will result in representative samples for each DU; this assumption is evaluated below.

\section{Analysis}

The glass containers were used for transport of samples for analysis for BTEX, hydrocarbons and PAHs, whereas the soil in Rilsan bags was used for dry weight determination and metal analysis. Only one replicate from the secondary sampling was analysed for each contamination type. BTEX and hydrocarbons were analysed according to RefLab method 1:2010, ${ }^{8}$ PAH's according to RefLab 4:2008, ${ }^{9}$ metals according to DS 259:2003 (extraction)/SM3120 (analysis) $)^{10,11}$ and dry weight according to DS 204:1980.12 All methods are accredited according to accreditation 168 (DANAK). Samples were kept at $4-5^{\circ} \mathrm{C}$ until analysis. All analysis were performed by Eurofins Environment Denmark.

\section{Results and discussion Levels and distribution of contaminants}

An overview of measured parameters is listed in Table 3 which shows information on the number and percentage of analysed samples for each parameter, percentage of samples above detection limits (DL) and min, max, mean and median concentrations.

Metals were detected in almost all samples, but with highly skewed distributions due to a few high concentrations. BTEXs were detected in only $10 \%$ or less of the samples. Light hydrocarbons (C10-C20) were detected in 26\% of the samples and heavy hydrocarbons ( $\mathrm{C} 20-$ C35) in 36\% of the samples. The distributions are extremely skewed with only few very high concentrations. For PAHs, most samples have concentrations close to $\mathrm{DL}$ or $<\mathrm{DL}$. The skewed distributions with many concentrations close to $\mathrm{DL}$ and few very high concentrations is typical of many contaminated sites with few contamination hotspots and low background levels for the remaining samples.
Even after taking the logarithm of the concentrations, the distribution for most of the compounds were still highly positively skewed (data not shown). The statistics reported here were consequently calculated based on concentrations >DL only.

Figure 4 shows how the contaminants are distributed across the sampling site. The plots show the average concentration over all sampling depths. The lowest level of the contour plot (deep blue colour) is for an average concentration below the threshold for uncontaminated soil, corresponding to class 0 .

It is evident that the site contains several hotspots with high contaminations, mainly along the borders of the area, highest in the north-west centre, but also in the east corner for PAHs and the south border for BTEX. The irregular spread of contaminants at the site is typical of its complex historical industrial use (production of glue, paint and lacquer, warehousing, stock rental and container rental with several tanks for storage of chemicals and waste).

Figure 5 shows the distribution of contaminants as a function of depth. The depth profiles are quite different for the various types of contaminants: Metals and PAHs decrease with depth, BTEX peaks at $0.8 \mathrm{~m}$, hydrocarbons decrease with depth, but have a double maximum at $0.5 \mathrm{~m}$ (for light hydrocarbon components) and $1.5 \mathrm{~m}$ for heavier components.

The most probable processes of contamination spreading (see typical processes in Guidelines on remediation of contaminated sites by the Danish $E A^{2}$ ) are unplanned breaks in local groundwater abstraction and multiple contaminations either spread directly, e.g. as spills, or indirectly as deposition of soil and waste (the entire soil above groundwater table is deposited). The groundwater potential in low-lying urban areas close to the sea, such as this site, is approximately at ground level. Typically, the groundwater level in such areas is regulated by abstraction to approximately $1.5 \mathrm{~m}$ below ground level. Apart from the primary industrial contamination sources, occasional changes of groundwater level and later deposition are the main contributors to the contamination spreading patterns at the site. 


\section{SAMVPLINE GOLEN}

Table 3. Compounds/parameters analysed. Concentrations are in $\mathrm{mg} \mathrm{kg}^{-1} \mathrm{dw}$ (dry weight). Statistics have only been calculated for concentrations $>$ DL.

\begin{tabular}{|c|c|c|c|c|c|c|c|}
\hline & Dry matter & $\mathrm{Pb}$ & $\mathrm{Cd}$ & $\mathrm{Cr}$ & $\mathrm{Cu}$ & $\mathrm{Ni}$ & $\mathrm{Zn}$ \\
\hline Results & 1792 & 1792 & 1792 & 1792 & 1792 & 1792 & 1792 \\
\hline Not measured & 0 & 0 & 0 & 0 & 0 & 0 & 0 \\
\hline Detected & 1792 & 1792 & 1729 & 1791 & 1792 & 1792 & 1792 \\
\hline \% Detected & 100 & 100 & 96 & 100 & 100 & 100 & 100 \\
\hline Min & 52 & 1.8 & 0.0 & 2.9 & 2.3 & 2.7 & 12 \\
\hline Max & 100 & 5000 & 18 & 7500 & 10000 & 270 & 16000 \\
\hline Mean & 88 & 59 & 0.3 & 25 & 92 & 15 & 180 \\
\hline Median & 89 & 11 & 0.1 & 17 & 15 & 14 & 40 \\
\hline \multirow[t]{2}{*}{ Mean/Median } & 1.0 & 5.4 & 2.4 & 1.5 & 6.1 & 1.1 & 4.5 \\
\hline & Benzene & Toluene & Ethylbenzene & o-Xylene & $m+p$-Xylene & Xylenes & BTEX \\
\hline Results & 1722 & 1722 & 1722 & 1722 & 1722 & 1719 & 1719 \\
\hline Not measured & 70 & 70 & 70 & 70 & 70 & 73 & 73 \\
\hline Detected & 15 & 65 & 101 & 93 & 141 & 153 & 165 \\
\hline \% Detected & 1 & 4 & 6 & 5 & 8 & 9 & 10 \\
\hline Min & 0.1 & 0.1 & 0.1 & 0.1 & 0.1 & 0.1 & 0.1 \\
\hline Max & 0.9 & 310 & 420 & 210 & 1300 & 1500 & 2200 \\
\hline Mean & 0.4 & 6.1 & 8.1 & 5.7 & 22 & 24 & 29 \\
\hline Median & 0.3 & 0.3 & 0.6 & 0.7 & 1.0 & 1.1 & 1.2 \\
\hline \multirow[t]{2}{*}{ Mean/Median } & 1.4 & 20 & 13 & 8.8 & 22 & 22 & 24 \\
\hline & $\mathrm{C} 6-\mathrm{C} 10$ & C10-C15 & C15-C20 & C20-C35 & $\mathrm{C} 10-\mathrm{C} 20$ & C6-C35 & \\
\hline Results & 1792 & 1792 & 1792 & 1792 & 1792 & 1792 & \\
\hline Not measured & 0 & 0 & 0 & 0 & 0 & 0 & \\
\hline Detected & 200 & 258 & 458 & 638 & 488 & 718 & \\
\hline \% Detected & 11 & 14 & 26 & 36 & 27 & 40 & \\
\hline Min & 2.0 & 5.0 & 5.1 & 20 & 5.1 & 2.0 & \\
\hline Max & 3700 & 6600 & 4400 & 9600 & 7000 & 12,000 & \\
\hline Mean & 130 & 220 & 110 & 270 & 220 & 420 & \\
\hline Median & 12 & 27 & 21 & 96 & 28 & 110 & \\
\hline \multirow[t]{2}{*}{ Mean/Median } & 11 & 8.4 & 5.0 & 2.8 & 7.7 & 3.9 & \\
\hline & $\mathrm{FI}$ & BbjkFI & BaPyr & Ipyr & DBahAnt & PAH & \\
\hline Results & 1786 & 1777 & 1777 & 1777 & 1777 & 1777 & \\
\hline Not measured & 6 & 15 & 15 & 15 & 15 & 15 & \\
\hline Detected & 1217 & 1321 & 1052 & 948 & 685 & 1328 & \\
\hline \% Detected & 68 & 74 & 59 & 53 & 39 & 75 & \\
\hline Min & 0.01 & 0.01 & 0.01 & 0.01 & 0.01 & 0.01 & \\
\hline Max & 420 & 210 & 120 & 68 & 16 & 830 & \\
\hline Mean & 1.8 & 1.2 & 0.8 & 0.5 & 0.2 & 4.0 & \\
\hline Median & 0.16 & 0.09 & 0.14 & 0.13 & 0.06 & 0.28 & \\
\hline Mean/Median & 11 & 13 & 5.9 & 4.2 & 2.9 & 14 & \\
\hline
\end{tabular}

Fl: fluoranthene; BbjkFl: Benzo(b+j+k)fluoranthene; BaPyr: Benz(a)pyrene; Ipyr: Indeno(1,2,3-cd)pyrene; DBahAnt: Dibenzo(a,h) anthracene 


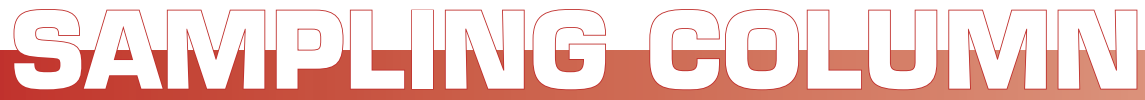
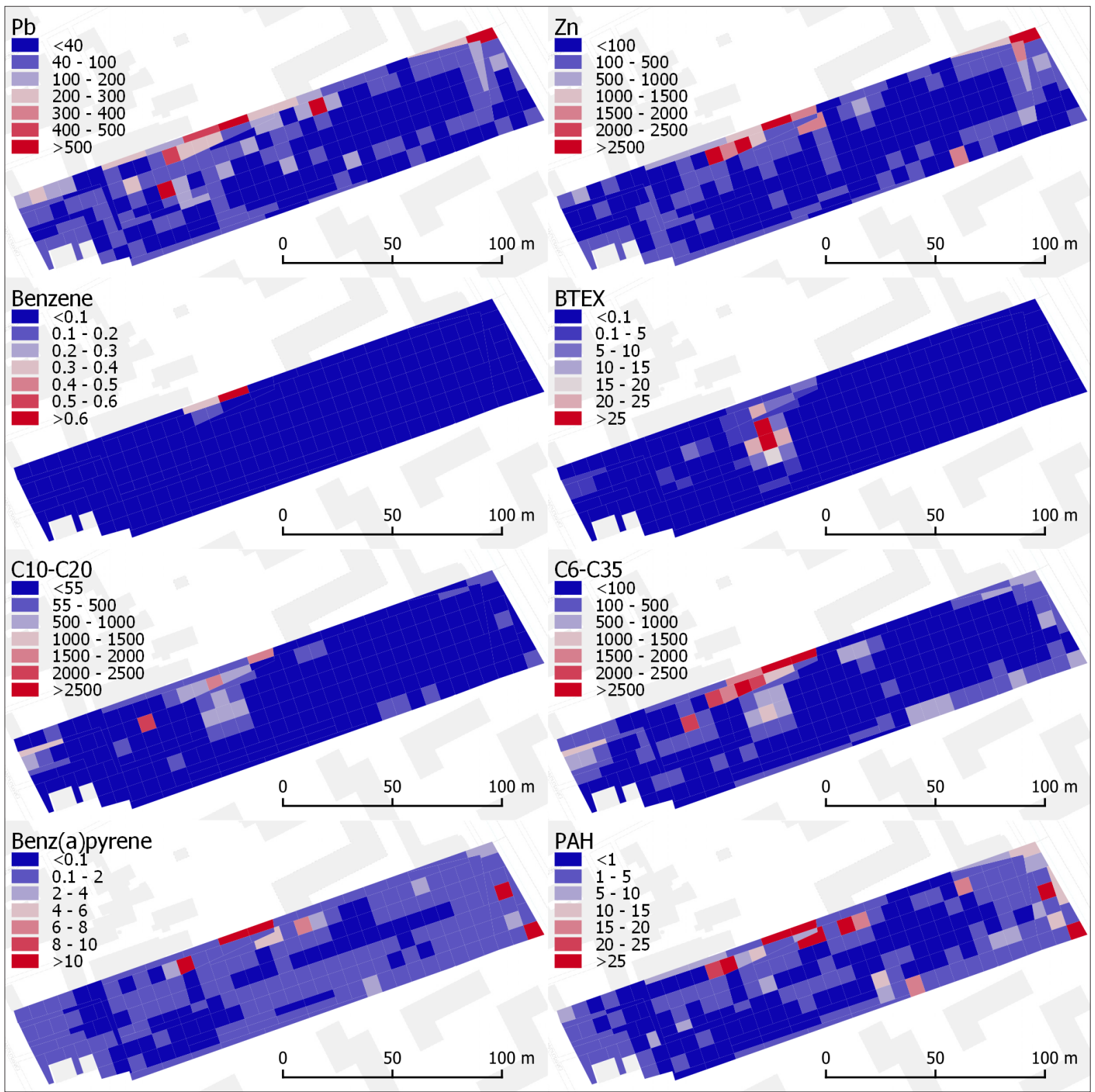

Figure 4. Distribution of contaminants across the industrial site. Average concentrations for all depths in $\mathrm{mg} \mathrm{kg}^{-1} \mathrm{dw}$. The lowest level (dark blue) is for concentration that would be classified as soil class 0 .

\section{Sampling uncertainty}

The total uncertainty (sampling + analysis) of the primary and secondary sampling was estimated based on 28 duplicate primary samples: 18 were collected at $0.17 \mathrm{~m}$ and 10 at a depth of $0.83 \mathrm{~m}$. The result given as the pooled relative standard deviation (RSD\%) for the determinations is listed in Table 4.

Thus, the RSD \% for a sample taken at the same position at the depths $0.17 \mathrm{~m}$ and $0.83 \mathrm{~m}$ was approximately $70 \%$. The influence of typical uncertainties for laboratory analysis is shown in Table 5.
As can be seen, the influence of the analytical uncertainty is only of minor importance compared to an average total sampling uncertainty of approximately $60-70 \%$. For comparison, an alternative way of estimating this uncertainty is to plot the standard deviation as function of the concentration. The slope of this line is equal to the RSD. The average $R S D$ for all analytes (excluding sums of xylenes etc.) was $61 \%$ when all samples were included and $68 \%$ when the highest concentrations were excluded.
In summary, the sampling uncertainty was at least $60-70 \%$. How much of this uncertainty was due to the primary sampling vs the secondary sampling could not be determined from the current experimental setup, as this would require duplicates for each step (primary and secondary sampling) separately.

\section{Soil classification errors}

How does this level of sampling uncertainty affect soil classification? This very important question can be illustrated in this study because all 


\section{SHMPLANE GoLEN}
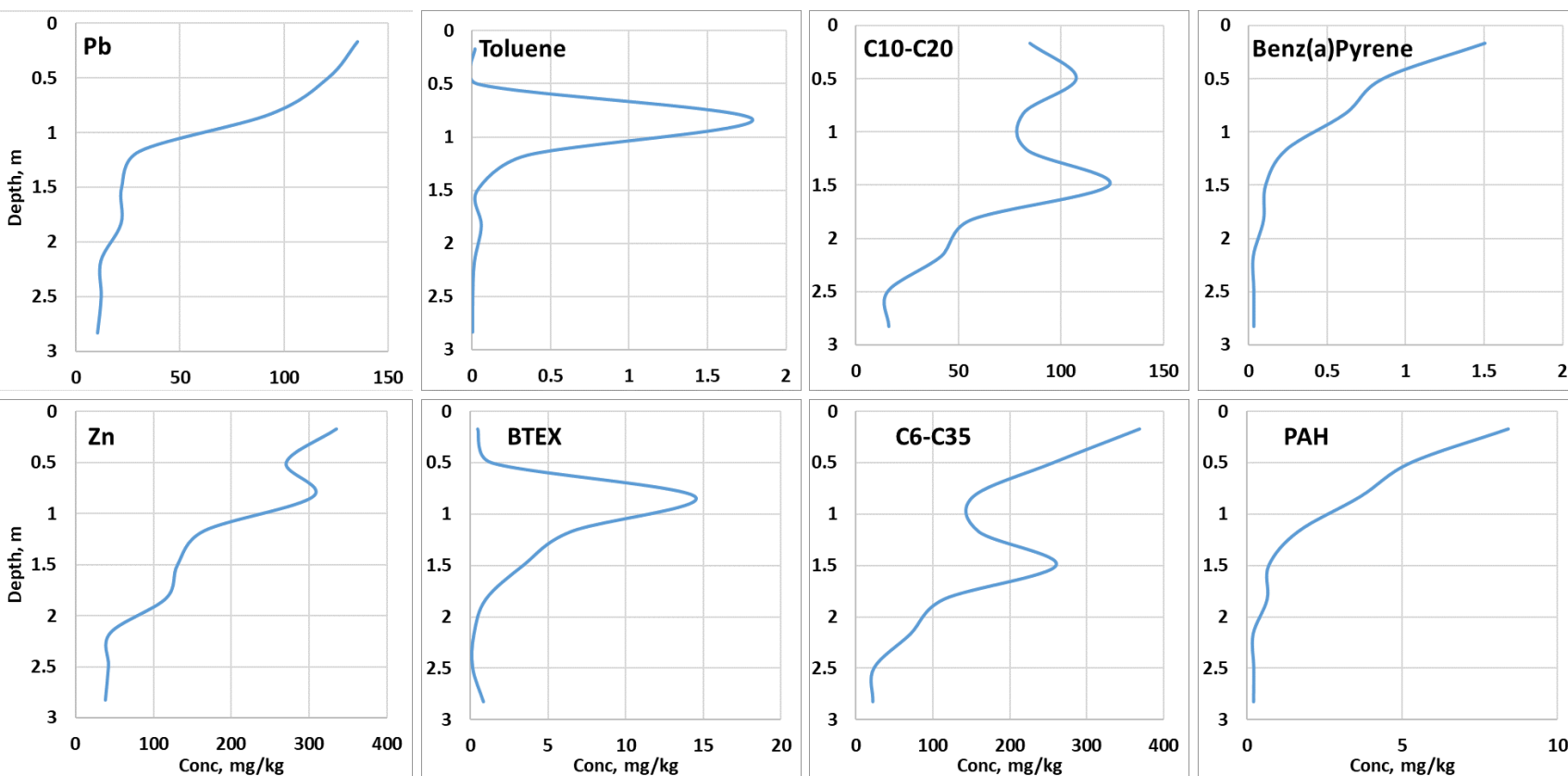

Figure 5. Average concentration in $\mathrm{mg} \mathrm{kg}^{-1} \mathrm{dw}$ as a function of depth $(0.00-3.00 \mathrm{~m})$.

Table 4. Total $R S D \%$ of sampling (sampling + analysis) determined from duplicate primary samples. ${ }^{a}$

\begin{tabular}{|c|c|c|c|c|c|c|c|}
\hline ALL & Metals & BTEX & Hydrocarbon & РАH & All contamin. & & \\
\hline RSD\% & 58 & 98 & 66 & 78 & 71 & & \\
\hline$N$ & 196 & 53 & 76 & 122 & 447 & & \\
\hline Metals & $\mathrm{Pb}$ & $\mathrm{Cd}$ & $\mathrm{Cr}$ & $\mathrm{Cu}$ & $\mathrm{Ni}$ & $\mathrm{Zn}$ & \\
\hline$R S D \%$ & 74 & 74 & 40 & 68 & 48 & 64 & \\
\hline N & 28 & 28 & 28 & 28 & 28 & 28 & \\
\hline BTEX & Benzene & Toluene & EthBz & $o$-Xylene & $m+p$-Xylene & Xylenes & BTEX \\
\hline RSD \% & 96 & 81 & 97 & 97 & 107 & 102 & 95 \\
\hline N & 4 & 6 & 8 & 8 & 9 & 9 & 9 \\
\hline Hydrocarbons & C6-C10 & $\mathrm{C} 10-\mathrm{C} 15$ & $\mathrm{C} 15-\mathrm{C} 20$ & C20-C35 & $\mathrm{C} 10-\mathrm{C} 20$ & C6-C35 & \\
\hline RSD $\%$ & 87 & 66 & 65 & 63 & 66 & 58 & \\
\hline$N$ & 13 & 15 & 22 & 26 & 22 & 26 & \\
\hline PAH & $\mathrm{FI}$ & BbjkFl & BaPyr & Ipyr & DBahAnt & PAH & \\
\hline RSD \% & 80 & 77 & 79 & 80 & 74 & 80 & \\
\hline$N$ & 27 & 25 & 24 & 24 & 22 & 28 & \\
\hline
\end{tabular}

aThese numbers include the minor analysis uncertainty

samples, both standard samples and Gandalf samples, are extracted by the same sampling procedure and with the same tools as are generally used in Denmark for soil classificationexcept that more increments (10) were used for the secondary sampling in the field.
The effect of sampling uncertainty on soil classification was investigated in three ways: 1) comparison of classification for the 28 duplicate primary samples, 2) comparison of classification according to standard samples and to Gandalf samples within the same grid $(7 \times 7 \times 0.33 \mathrm{~m})$ and 3$)$ a detailed analysis of which compounds are the most influential regarding soil classification.

The results of comparison of the 28 duplicate primary samples and comparison of classification of standard samples with Gandalf samples are shown in Table 6. 
Table 5. Uncertainty of sampling (RSD\%) when analytical uncertainty is subtracted. ${ }^{a}$

\begin{tabular}{|c|c|c|c|}
\hline $\begin{array}{c}\text { Total } \\
\text { RSD \% }\end{array}$ & \multicolumn{3}{|c|}{ Analysis RSD \% } \\
\hline & 5 & 10 & 20 \\
\hline 30 & 30 & 28 & 22 \\
\hline 40 & 40 & 39 & 35 \\
\hline 50 & 50 & 49 & 46 \\
\hline 60 & 60 & 59 & 57 \\
\hline 70 & 70 & 69 & 67 \\
\hline 80 & 80 & 79 & 77 \\
\hline
\end{tabular}

${ }^{\mathrm{a}}$ Sampling RSD \% = $\sqrt{(\text { Total RSD \% })^{2}-(\text { Analysis RSD \% })^{2}}$

Table 6 shows that $53 \%$ of the investigated sites were classified differently [standard sample vs the associated duplicate or w.r.t. Gandalf samples (Sum \% abs for all samples)]. Soil classification errors increase as function of distance away from the standard sample location up to a distance of $2 \mathrm{~m}(32 \%, 49 \%, 58 \%$ and $57 \%$ for $0 \mathrm{~m}, 1 \mathrm{~m}, 2 \mathrm{~m}$ and $3 \mathrm{~m}$, respectively).

Table 6. Soil classification errors for duplicates and Gandalf samples relative to standard samples. The column \% abs is percent sample with an absolute difference of one to four classes. Bin is the distance from the original standard sample soil class $(-4,-3$, $-2,-1$ indicate classification $1-4$ less), while positive values $(1,2,3,4)$ indicate classification above the original standard sample.

\begin{tabular}{|c|c|c|c|}
\hline \multicolumn{4}{|c|}{ All samples, duplicates + Gandalf } \\
\hline Bin & Frequency & $\%$ & $\%$ abs \\
\hline-4 & 0 & 0 & \\
\hline-3 & 13 & 4 & \\
\hline-2 & 19 & 6 & \\
\hline-1 & 63 & 20 & \\
\hline 0 & 147 & 47 & \\
\hline 1 & 45 & 14 & 34 \\
\hline 2 & 21 & 7 & 13 \\
\hline 3 & 5 & 2 & 6 \\
\hline 4 & 2 & 1 & 1 \\
\hline Sum & 315 & 100 & 53 \\
\hline
\end{tabular}

The lesson learned from this survey is that two primary samples taken from the same DU, 30 ton soil, gave rise to different soil classifications in one-third of the cases if two samples were taken at the exact same position, but in half of the cases if the samples are extracted at various other distances from within the same DU. These levels of misclassification must be considered as minimum estimates as the sampling procedure in this study is improved over the standard approach by using 10 increments for the secondary sub-sampling in contrast to the normal procedure of only one increment. An overview with the average difference between classifications, i.e. the global classification error is given in Table 7 .

Table 8 shows the classification of all 1792 soil samples according to individual contaminants.

The contaminants responsible for most of the classification as contaminated soil (class 1-4), were Pb, $\mathrm{Ni}, \mathrm{Zn}$, heavy hydrocarbons, Benz(a)pyrene and sum PAHs.

The results in Table 8 denote classification for one contaminant (or contaminant type) regardless of classification by other contaminants.

The difference in classification for the different types of contaminants was 53\% for metals, 6\% for BTEX, 33\% for hydrocarbons and $40 \%$ for PAHs.

Metals showed the highest classification difference (in relative percentages), whereas the lower percentages for $\mathrm{PAHs}$, hydrocarbons and especially BTEX reflect that very many were $<D L$ resulting in a classification as class 0 according to these compounds.

\section{Conclusions}

Classification of excavated soil is crucial for correct handling and eventual reuse. Based on the official sampling strategies used in Denmark, the present large-scale investigation clearly identifies primary and secondary sampling as the main factors affecting classification of contaminated soils. At least $50 \%$ of all samples were misclassified, 20\% were misclassified by two or more classes. This study demonstrates that the risk of misclassification is highest for less mobile parameters, metals and PAHs compared to the volatile organic solvents.

The risk of misclassification goes two ways, both leading to under- as well as overestimation of the environmental risk class for the physical soil DUs. Overestimation in the form of classification of excavated soil into higher contamination classes will result in inefficient use of the soil resource by restricting its possible reuse unnecessarily-or lead to unnecessary deposition at landfills, which typically also lead to elevated transportation and deposition costs. In contrast, soil class underestimation is a de facto underassessment of the environmental risk, which may result in unnecessary exposure to the environment and/or to the public causing unwanted and unknown health and other risks.

The present study demonstrates that for soil contamination, sampling uncertainty dominantly exceed the uncertainty from laboratory analysis. However, misclassification can be reduced significantly by implementation of appropriate strategies for representative sampling.

Table 7. Soil classification error from two samples from the same 30 tons primary sample. $N$ indicate the number of samples, $N$ (error) how many samples have different classifications, $\%$ Error is the percentage of wrong classifications, while Mean error indicates the mean error in the classification.

\begin{tabular}{|c|c|c|c|c|}
\hline $\begin{array}{c}\text { Distance } \\
(\mathrm{m})\end{array}$ & $\boldsymbol{N}$ & N(error) & \% Error & Mean error, classes \\
\hline 0 & 28 & 9 & 32 & 0.7 \\
\hline 1 & 81 & 40 & 49 & 1.0 \\
\hline 2 & 96 & 56 & 58 & 1.2 \\
\hline 3 & 110 & 63 & 57 & 1.1 \\
\hline All & 315 & 168 & 53 & 1.1 \\
\hline
\end{tabular}




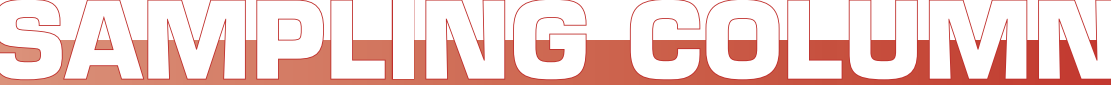

Table 8. Soil classification according to individual contaminants.

\begin{tabular}{|c|c|c|c|c|c|c|}
\hline Soil classification & $\mathrm{Pb}$ & $\mathrm{Cd}$ & $\mathrm{Cr}$ & $\mathrm{Cu}$ & $\mathrm{Ni}$ & $\mathrm{Zn}$ \\
\hline Class & $(\%)$ & $(\%)$ & $(\%)$ & $(\%)$ & $(\%)$ & $(\%)$ \\
\hline 0 & 70 & 89 & 98 & 73 & 67 & 77 \\
\hline 1 & 0 & 0 & 2 & 25 & 30 & 17 \\
\hline 2 & 18 & 6 & 0 & 0 & 2 & 0 \\
\hline 3 & 10 & 5 & 0 & 1 & 2 & 4 \\
\hline 4 & 2 & 0 & 0 & 2 & 0 & 2 \\
\hline Class $>0$ & 30 & 11 & 2 & 27 & 33 & 23 \\
\hline Soil classification & C6-C10 & $\begin{array}{c}\mathrm{C} 10- \\
\mathrm{C} 15\end{array}$ & $\begin{array}{l}\text { C15- } \\
\text { C20 }\end{array}$ & $\begin{array}{c}\text { C20- } \\
\text { C35 }\end{array}$ & $\begin{array}{l}\mathrm{C} 10- \\
\mathrm{C} 20\end{array}$ & C6-C35 \\
\hline Class & $(\%)$ & $(\%)$ & $(\%)$ & $(\%)$ & $(\%)$ & $(\%)$ \\
\hline 0 & 96 & 94 & 94 & 83 & 91 & 79 \\
\hline 1 & 0 & 0 & 0 & 0 & 0 & 0 \\
\hline 2 & 1 & 1 & 1 & 6 & 2 & 7 \\
\hline 3 & 0 & 1 & 1 & 4 & 1 & 3 \\
\hline 4 & 3 & 5 & 4 & 7 & 6 & 10 \\
\hline Class $>0$ & 4 & 6 & 6 & 17 & 9 & 21 \\
\hline Soil classification & Benzene & BTEX & BaPyr & DBahAnt & $\mathrm{PAH}$ & \\
\hline Class & $(\%)$ & $(\%)$ & $(\%)$ & $(\%)$ & $(\%)$ & \\
\hline 0 & 99 & 94 & 67 & 87 & 72 & \\
\hline 1 & 0 & 0 & 9 & 9 & 16 & \\
\hline 2 & 1 & 4 & 15 & 2 & 10 & \\
\hline 3 & 0 & 0 & 7 & 1 & 2 & \\
\hline 4 & 0 & 2 & 2 & 1 & 1 & \\
\hline Class $>0$ & 1 & 6 & 33 & 13 & 28 & \\
\hline
\end{tabular}

Methods are readily at hand as described in the TOS framework. ${ }^{13-15}$

\section{Regulatory implications}

We recommend that the risks for misclassification demonstrated in this study should be addressed by the relevant environmental authorities through review and renewal of exploration plans for future entrepreneurial projects in former industrial areas, a.o. using DUs dependent on the contamination type. ${ }^{16}$ The estimated misclassification and contamination levels at former industrial sites should be assessed together w.r.t. the prevailing hydro-geochemical conditions at the relevant sites.

In Denmark the quality of laboratory analysis is controlled through national quality control schemes and
4. Bekendtgorelse om Anmeldelse og Dokumenation I Forbindelse Med Flytning a Fjord (Regulation for transport of soil). BEK No. 1452 (2015).

5. Bekendtgorelse om Anvendelse af Restprodukter, Jord og Sorteret Bygge- og Anlægsaffald (Reuse of Waste, Soil and Building Materials). BEK No. 1672 (2016).

6. https://www.regionsjaelland.dk/ Miljo/jordforurening/Publikationer/ Documents/jordvejledning-sjaelland-juli-2001-med-rettelser.pdf [accessed 9-7-2021].

7. Ansogning i Henhold Til §8 i Lov Om Forurenet Jord Om Tilladelse Til Anlægs- Og Gravearbejde Samt AEndret Arealanvendelse i Forbindelse Med Opforelse Af Boligbyggeri (not publicly available).

8. https://cdnmedia.eurofins.com/ Microsites/media/1947/metode-1olie-i-jord-2-udgave-2010.pdf

9. https://cdnmedia.eurofins. com/Microsites/media/1148/ metode_4_2008_2_udg.pdf

10. https://webshop.ds.dk/en-gb/standard/ds-2592003? CurrencyCode=EU R\&pagesize $=100 \&$ print $=$ true

11. https://www.nemi.gov/methods/ method_summary/4699/

12. https://webshop.ds.dk/en-gb/ standard/milj\%C3\%B8unders\%C3 \%B8gelser/ds-2041980

13. P.M. Gy, Sampling for Analytical Purposes. John Wiley (1999). ISBN 978-0-471-97956-2

accreditations as opposed to, e.g., establishment of TOS-compliant sampling strategies. This study demonstrates that improvements of the data quality and thus the quality of later conclusions and actions are most efficiently met by focusing on the processes before representative samples are analysed in laboratories.

\section{References}

1. https://www2.mst.dk/Udgiv/ Publications/2001/87-7944-519-5/ Html/Kap06 eng.Htm\#kap6.1.2, [accessed 9-7-2021].

2. https://www2.mst.dk/udgiv/publications/2002/87-7972-280-6/pdf/877972-281-4.pdf

3. Bekendtgrelse af lov om Forurenet Jord (Regulation of Contaminated Soil). LBK No. 282 (2007).
14. P. Minkkinen, "Practical applications of sampling theory", Chemometr. Intell. Lab. Sys. 74(1), 85-94 (2004). https://doi.org/10.1016/j.chemolab.2004.03.013

15. K.H. Esbensen, Introduction to the Theory and Practice of Sampling. IM Publications Open, Chichester (2020). https://doi. org/10.1255/978-1-906715-29-8

16. C. Ramsey, "Considerations for inference to decision units", J. AOAC Int. 98(2), 288-294 (2015). https://doi. org/10.5740/jaoacint.14-292 


\section{SANDLANE GOLEHWN}
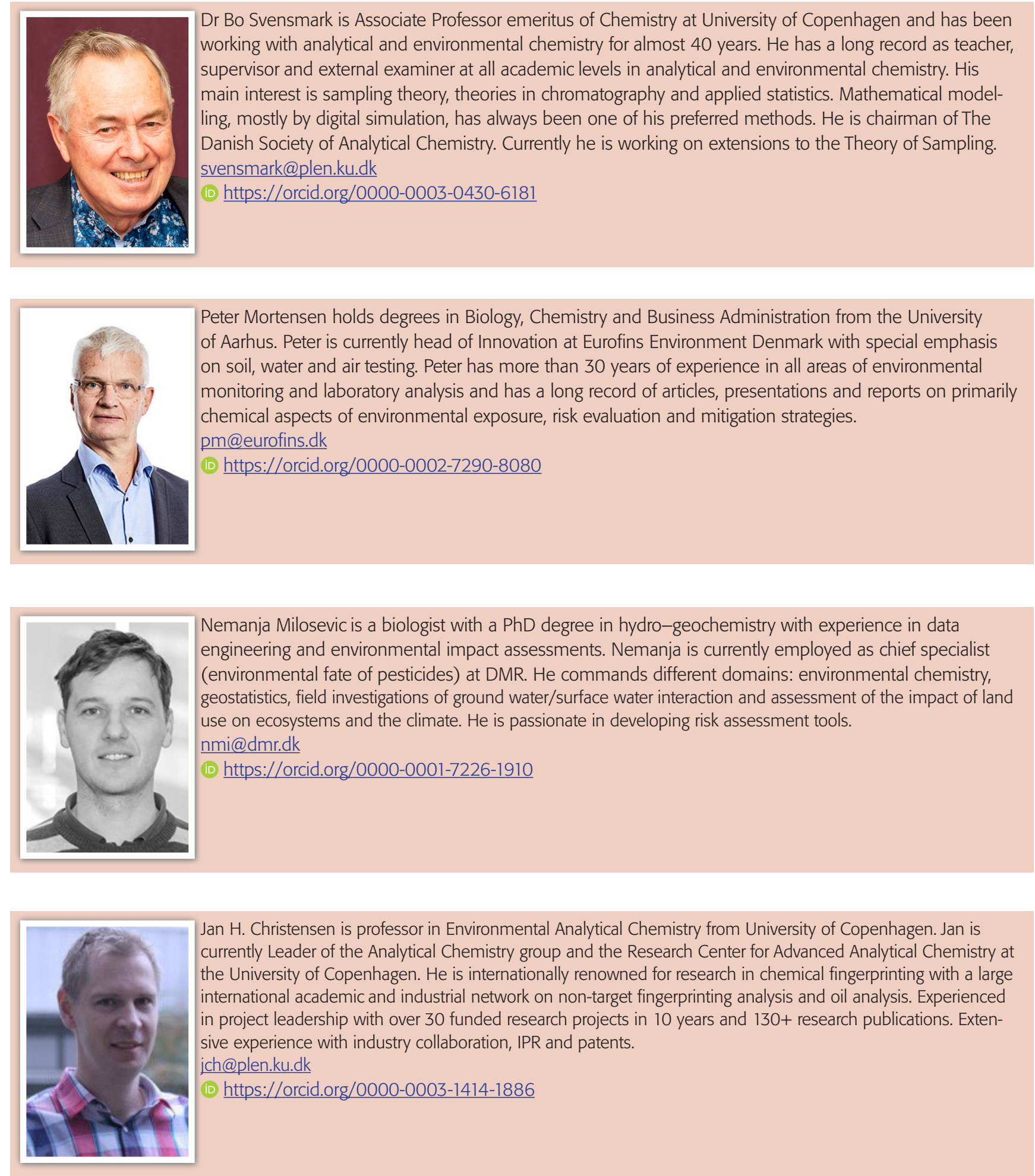


\section{Introduction to the Theory and Practice of Sampling}

\section{Kim H. Esbensen}

with contributions from Claas Wagner, Pentti Minkkinen, Claudia Paoletti, Karin Engström, Martin Lischka and Jørgen Riis Pedersen

"Sampling is not gambling". Analytical results forming the basis for decision making in science, technology, industry and society must be relevant, valid and reliable. However, analytical results cannot be detached from the specific conditions under which they originated. Sampling comes to the fore as a critical success factor before analysis, which should only be made on documented representative samples. There is a

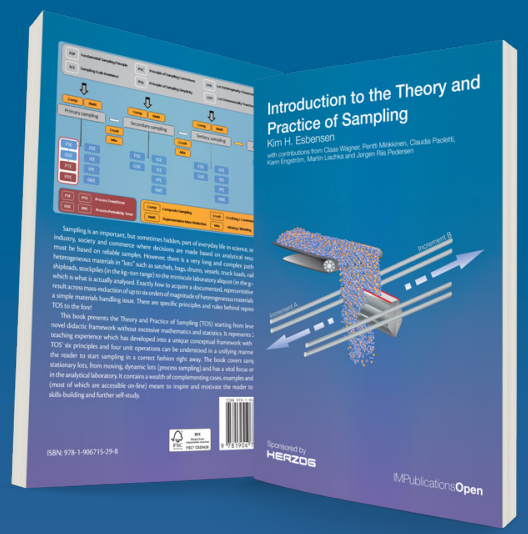
complex and challenging pathway from heterogeneous materials in "lots" such as satchels, bags, drums, vessels, truck loads, railroad cars, shiploads, stockpiles (in the $\mathrm{kg}$-ton range) to the miniscule laboratory aliquot (in the $\mathrm{g}-\mu \mathrm{g}$ range), which is what is actually analysed.

This book presents the Theory and Practice of Sampling (TOS) starting from level zero in a novel didactic framework without excessive mathematics and statistics. The book covers sampling from stationary lots, from moving, dynamic lots (process sampling) and has a vital focus on sampling in the analytical laboratory.

"I recommend this book to all newcomers to TOS"

"This book may well end up being the standard introduction sourcebook for representative sampling." "One of the book's major advantages is the lavish use of carefully designed didactic diagrams"

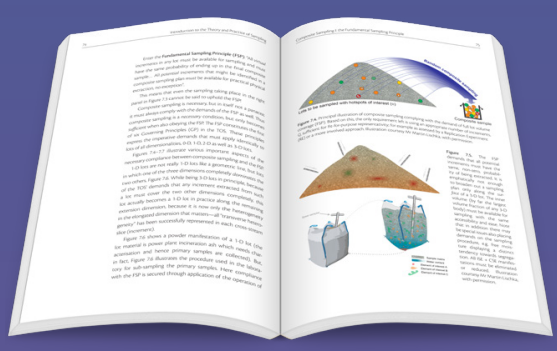

